\title{
Accurate analytical evaluation of fugacity coefficient of gases
}

\author{
E. Somuncu ${ }^{1}$ \\ ${ }^{1}$ Giresun Universitesi
}

August 10, 2020

\begin{abstract}
In this study, we proposed an alternative analytical procedure for appraising the fugacity coefficient for gases using second virial coefficient with Lennard-Jones (12-6) potential. The present research is more efficient for determining of the fugacity coefficient of gases in wide ranges temperature and pressure ranges and related thermodynamic properties which is the novelty of this study. The fugacity coefficient for gases, , and has calculated in the temperature range from $30 \mathrm{~K}$ to $1000 \mathrm{~K}$ and pressure range from $0.1 \mathrm{~atm}$ to $200 \mathrm{~atm}$ by using the obtained analytical formula. To our knowledge, this work offers the first approximation to the evaluation of the fugacity coefficient for gases for and by second virial coefficients. The results obtained using the analytical formula of the fugacity coefficient is in good agreement with literature.
\end{abstract}

\section{Hosted file}

fugacity coefficient son.docx available at https://authorea.com/users/350054/articles/475008accurate-analytical-evaluation-of-fugacity-coefficient-of-gases 